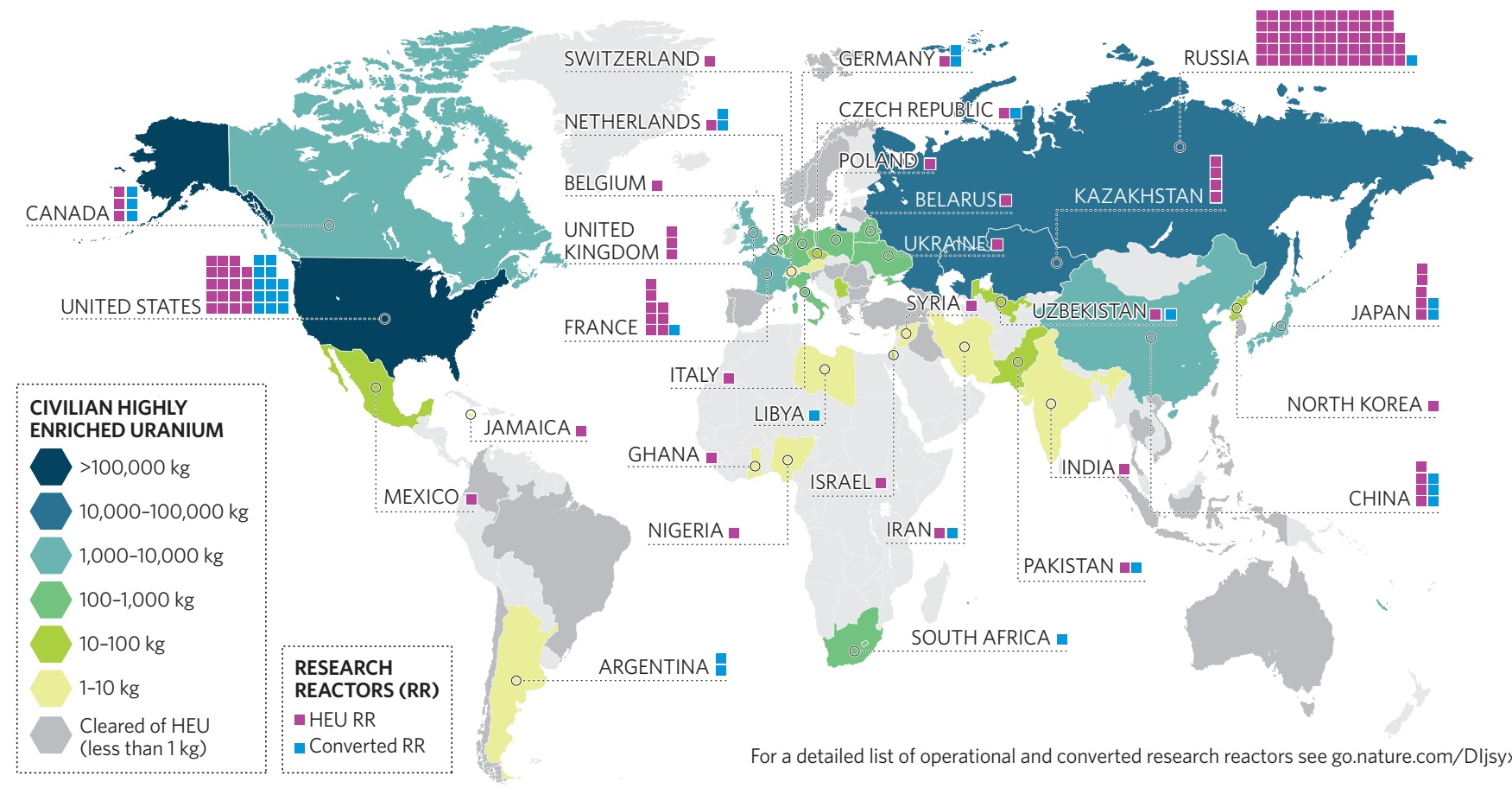

\title{
How to rid reactors of uranium risk
}

As the month-long conference reviewing the Nuclear Non-Proliferation Treaty comes to an end this week in New York, efforts to minimize the world's nuclear arsenal are centre stage.

But many countries at the meeting, held every 5 years, are calling for action on an underappreciated but pressing risk: getting rid of the legacy of hundreds of research reactors, mainly civilian, that use weapons-grade highly enriched uranium (HEU).

The total quantity of HEU in research reactors is small compared with military stocks, but still amounts to a few hundred tonnes - more than enough to pose a threat, as a nuclear bomb can be made with just a few dozen kilograms. Security can often be lower at research reactors, which are typically operated by universities and civilian labs, raising fears that nuclear material could fall into the hands of terrorists.

The Vienna-based International Atomic Energy Agency (IAEA) has been helping countries convert their reactors to use low-enriched uranium (LEU), but cannot force them to do so. Nations including the United States want a renewed worldwide effort to speed up this process; in April, President Barack Obama hosted an international nuclear security summit in Washington DC, which agreed in principle to the ambitious goal of locking down unsecured civilian nuclear material within 4 years.

Yet progress in converting HEU reactors to LEU has been slow (see map). Despite the renewed momentum for change, many of the resolutions supporting reactor conversion at this month's conference contained key caveats, such as "where this is technically and economically feasible".

Nature discussed the problem and possible solutions with Pablo Adelfang, head of the IAEA Research Reactor Section.

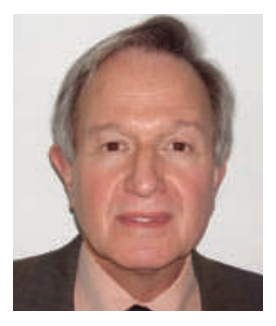

How important are HEU reactors for research?

Very. Research reactors are the cornerstone of nuclear science and a stepping stone towards nuclear power. They are unique tools for testing materials and fuel, and for training scientists and engineers. Other civilian HEU reactors, which share many of the design characteristics of HEU research reactors, produce vital medical radioisotopes.

How secure are HEU stocks against theft? Security standards have improved widely. Some of the HEU is so highly irradiated that it would quickly kill anyone trying to steal it. But there is a dispute over what levels of irradiation make HEU self-protecting. Some material that has been cooling in a pool is less lethal, and one could imagine terrorists taking the risk of stealing it.

Why are reactors difficult to convert? HEU reactors used for research and to produce medical radioisotopes have uranium enrichment levels of the order of 90\% fissile uranium-235 atoms and just $10 \%$ uranium-238. [Unenriched uranium is largely non-fissile, containing about $99 \%$ uranium-238.] The problem is that the volume of the core of these existing HEU reactors, and their component fuel elements, are fixed by their initial design. You cannot increase the size of the core, which would be one way to achieve almost the same number of uranium-235 atoms in the core using LEU (typically about $20 \%$ enriched). In any case, that would amount to designing a new reactor.

So the only option for conversion is to design LEU fuels with higher densities of uranium. The challenge has been to increase fuel density while ensuring that fuels can be easily fabricated and will perform properly under irradiation to accommodate released fission gases, for example. Fortunately, almost all HEU research reactors were designed as relatively low-power, low-fuel-density reactors. That means the high-density LEU fuels already available are adequate for 
converting them. But that leaves 20 or so higher power, higher performance HEU reactors, which would require LEU fuel of much higher density to match the uranium-235 loading of their HEU cores.

\section{How are researchers trying to create higher density LEU fuels?}

The highest possible density for a uranium fuel is pure uranium metal, but it is unstable under reactor conditions. So it is alloyed with other elements, typically molybdenum at $7-8 \%$. The density of a uranium-molybdenum alloy is very close to that of pure uranium.

But in tests in 2003, the first promising next-generation LEU fuel - in which the uranium-molybdenum powder was dispersed in a heat-conducting aluminium matrix - failed badly. The fuel reacted with the matrix, became amorphous, and was unable to retain fission gases, which gathered together in big bubbles, causing breakaway swelling of the fuel and pillowing of the fuel plates. One solution was to add pure silicon to either the fuel or the aluminium. Another, the main route being pursued, was to use aluminium as a cladding rather than a matrix, with a thin layer of zirconium separating it from a sheet of uranium. Final development and qualification of this latter fuel should take just a couple of years. It would allow conversion of all but about ten HEU reactors.

\section{Is cost an obstacle to conversion?}

Converting a reactor can cost from US\$1 million to \$10 million, depending on its type. The main expenses are purchasing new fuels and making changes to the reactor's safety and operating systems. These costs are met by most countries, although the Global Threat Reduction Initiative, a programme launched in 2004 by the US energy department to improve nuclear security worldwide, provides technical and funding support to lower-income countries.

The IAEA cannot demand conversion, but should countries wish to convert, we will provide technical support. There is some reluctance from scientists because they fear that conversion might reduce reactor performance. To reassure them, the IAEA does a detailed reactor assessment, including calculating any changes in performance.

\section{What's happening with medical reactors?}

Less progress has been made in converting the targets used for medical radioisotope production to LEU, although South Africa is converting one. Other countries, including Argentina and Australia, are already using LEU for this purpose. I think that the companies who produce radioisotopes are inclined to convert, but they are concerned about costs and the effect on the price of their products. A 2009 report by the US National Academies, however, found that there was no technical obstacle to converting, and that it would cause at most a $10 \%$ increase in the cost of medical imaging.

\section{What should happen next?}

We need to move on from debating whether it is economically or technically viable to convert HEU reactors and targets, and push ahead with doing it. The non-proliferation stakes are too high to do otherwise.

Declan Butler 